\title{
Oxygen-glucose deprivation induces ATP release via maxi-anion channels in astrocytes
}

\author{
Hong-Tao Liu • Ravshan Z. Sabirov • Yasunobu Okada
}

Received: 24 October 2006 / Accepted: 22 August 2007 / Published online: 12 September 2007

(C) Springer Science + Business Media B.V. 2007

\begin{abstract}
ATP represents a major gliotransmitter that serves as a signaling molecule for the cross talk between glial and neuronal cells. ATP has been shown to be released by astrocytes in response to a number of stimuli under nonischemic conditions. In this study, using a luciferinluciferase assay, we found that mouse astrocytes in primary culture also exhibit massive release of ATP in response to ischemic stress mimicked by oxygen-glucose deprivation (OGD). Using a biosensor technique, the local ATP concentration at the surface of single astrocytes was found to increase to around $4 \mu \mathrm{M}$. The OGD-induced ATP release was inhibited by $\mathrm{Gd}^{3+}$ and arachidonic acid but not by blockers of volume-sensitive outwardly rectifying $\mathrm{Cl}^{-}$ channels, cystic fibrosis transmembrane conductance regu-
\end{abstract}

H.-T. Liu $\cdot$ R. Z. Sabirov $•$ Y. Okada $(\bowtie)$

Department of Cell Physiology,

National Institute for Physiological Sciences,

Myodaiji-cho,

Okazaki 444-8585, Japan

e-mail: okada@nips.ac.jp

H.-T. Liu • Y. Okada

Department of Physiological Sciences, School of Life Science,

The Graduate University for Advanced Studies (SOKENDAI),

Okazaki 444-8585, Japan

R. Z. Sabirov

Department of Biophysics, National University,

700174 Tashkent, Vuzgorodok, Uzbekistan

H.-T. Liu

Department of Anesthesiology, The First Affiliated Hospital,

China Medical University,

Shenyang 110001, China lator (CFTR), multidrug resistance-related protein (MRP), connexin or pannexin hemichannels, $\mathrm{P} 2 \mathrm{X}_{7}$ receptors, and exocytotic vesicular transport. In cell-attached patches on single astrocytes, OGD caused activation of maxi-anion channels that were sensitive to $\mathrm{Gd}^{3+}$ and arachidonic acid. The channel was found to be permeable to $\mathrm{ATP}^{4-}$ with a permeability ratio of $\mathrm{P}_{\mathrm{ATP}} / \mathrm{P}_{\mathrm{Cl}}=0.11$. Thus, it is concluded that ischemic stress induces ATP release from astrocytes and that the maxi-anion channel may serve as a major ATPreleasing pathway under ischemic conditions.

Keywords Astrocytes - ATP release - Maxi-anion channel Oxygen-glucose deprivation

$\begin{array}{ll}\text { Abbreviations } \\ \text { ATP } & \text { adenosine 5'-triphosphate } \\ \text { BAPTA- } & 1,2 \text {-bis }(o \text {-aminophenoxyl)ethane- } N, N, N \text { ', } \\ \text { AM } & N^{\prime} \text {-tetraacetic acid tetra(acetoxymethyl) ester } \\ \text { BFA } & \text { brefeldin A } \\ \text { CFTR } & \text { cystic fibrosis transmembrane conductance } \\ & \text { regulator } \\ \text { EDTA } & \text { ethylenediaminetetraacetic acid } \\ \text { EGTA } & \text { ethylene glycol bis( } \beta \text {-aminoethylether)- } N, N, \\ & N ', N \text {-tetraacetic acid } \\ \text { FBS } & \text { fetal bovine serum } \\ \text { HEPES } & N \text {-(2-hydroxyethyl)piperazine- } \\ & N \text { - }(2 \text {-ethanesulfonic acid) } \\ \text { MDR } & \text { multidrug resistance protein } \\ \text { MEM } & \text { minimum essential medium } \\ \text { MRP } & \text { multidrug resistance-related protein } \\ \text { OGD } & \text { oxygen-glucose deprivation } \\ \text { TBOA } & \text { DL-threo- } \beta \text {-benzyloxyaspartate } \\ \text { VSOR } & \text { volume-sensitive outwardly rectifying }\end{array}$




\section{Introduction}

Astrocytes do not merely support, but actively regulate, neuronal functions by forming highly elaborate networks with other astrocytes and neurons [1-4]. Astrocytes communicate with neurons by releasing extracellular signaling molecules such as ATP and glutamate, while they communicate with each other via gap junctions, in addition to these gliotransmitters. Astrocytic ATP release has been shown to be induced in response to receptor stimulation by UTP [5], glutamate [6], and noradrenaline [7], to mechanical stimulation [8-10], to osmotic swelling [11], and to exposure to low $\mathrm{Ca}^{2+}$ solution [8, 9, 12]. Although ischemic stress is known to induce ATP release from rat hippocampal slices [13], it is not known whether astrocytes respond to ischemia with ATP release. The first purpose of the present study was to address this question.

Astrocytes express maxi-anion channels with a large single-channel conductance of 200-400 pS [14-16]. Recently, we have demonstrated that astrocytic maxi-anion channels are activated by chemical ischemia and serve as one of the major pathways for glutamate release [17]. The maxi-anion channel was found to possess a pore with a size large enough to permeate ATP [18] and was found to actually conduct anionic forms of ATP in mammary C127 cells under hypotonic conditions [19], in kidney macula densa cells in response to increased luminal $\mathrm{NaCl}$ concentrations [20], and in cardiac myocytes under hypotonic or ischemic conditions [21]. Thus, there is a possibility that maxi-anion channels serve as one of the pathways for ATP release from astrocytes under ischemic conditions. The second purpose of this study was to test this possibility.

\section{Materials and methods}

Cells

Astrocytes were obtained from neonatal mouse brain cortex and cultured, as previously described [17, 22], in Eagle's MEM supplemented with L-glutamine, $100 \mathrm{U} / \mathrm{ml}$ penicillin, $0.1 \mathrm{mg} / \mathrm{ml}$ streptomycin, $10 \% \mathrm{FBS}$, and $2.2 \mathrm{mg} / \mathrm{ml}$ $\mathrm{NaHCO}_{3}$.

HEK293 cells stably transfected with recombinant $\mathrm{P} 2 \mathrm{X}_{2}$ purinergic receptors were prepared and cultured, as described elsewhere [23]. The HEK-P2X 2 cells were used after dissociation into single cells and culturing in suspension for over $10 \mathrm{~min}$.

Solutions and chemicals

The standard Ringer solution contained (mM): $135 \mathrm{NaCl}, 5$ $\mathrm{KCl}, 2 \mathrm{CaCl}_{2}, 1 \mathrm{MgCl}_{2}, 5 \mathrm{Na}$-HEPES, 6 HEPES, and 5 glucose ( $\mathrm{pH} 7.4,290$ mosmol/ $\mathrm{kg} \mathrm{H}_{2} \mathrm{O}$ ). For inside-out experiments, we used standard Ringer solution both in the bath and in the pipette. The pipette solution for biosensor whole-cell experiments contained $(\mathrm{mM}): 125 \mathrm{CsCl}, 2$ $\mathrm{CaCl}_{2}, 1 \mathrm{MgCl}_{2}, 10$ EGTA, and 5 HEPES (pCa 7.6, 275 mosmol/kg $\mathrm{H}_{2} \mathrm{O}$, pH 7.4 adjusted with $\mathrm{CsOH}$ ). For ATP conductance measurements in the inside-out configuration, the bath solution was substituted with a solution of $100 \mathrm{mM} \mathrm{Na} \mathrm{mATP}_{4}$.

Oxygen-glucose deprivation (OGD) stress was applied by switching the perfusate from the standard Ringer solution to the OGD solution. The OGD solution was prepared by replacing D-glucose in Ringer solution with 2deoxyglucose and was continuously bubbled with $100 \%$ argon gas for more than $1 \mathrm{~h}$ before and during experiments. The oxygen concentration $\left(\mathrm{pO}_{2}\right)$ measured using an oxygen sensor (LICOX A3R, GMS, Kiel-Mielkendorf, Germany) was $118.4 \pm 1.1 \mathrm{mmHg}(n=8)$ for standard Ringer solution exposed to air in the experimental perfusion chamber. Under OGD conditions, the oxygen concentration in the perfusate solution decreased to a stable value of $7.5 \pm$ $0.6 \mathrm{mmHg}(n=9)$ at the inlet and $40.1 \pm 1.8 \mathrm{mmHg}(n=8)$ at the outlet of the experimental patch-clamp chamber.

$\mathrm{GdCl}_{3}$ was stored as a $50-\mathrm{mM}$ stock solution in water and added directly to solutions immediately before each experiment. Arachidonic acid, phloretin, brefeldin A (BFA), 1-octanol, probenecid, glibenclamide, and apyrase were purchased from Sigma-Aldrich (St. Louis, MO, USA) and BAPTA-AM from DOJINDO (Kumamoto, Japan); they were added to solutions immediately before use from stock solutions in DMSO. DMSO did not have any effect when added alone at concentrations employed in the present study (less than $0.1 \%$ ).

Osmolality of all solutions was measured using a freezing-point depression osmometer (OM802, Vogel, Kevelaer, Germany).

Luciferin-luciferase ATP assay

The bulk extracellular ATP concentration was measured by a luciferin-luciferase assay (ATP Luminescence Kit; AF2L1, DKK-TOA, Tokyo, Japan) with an ATP analyzer (AF100, DKK-TOA, Tokyo, Japan), as previously described [19, 21, 24], using astrocytes cultured in 12- or 24-well plates. After the culture medium was totally replaced with isotonic Ringer solution (1,000 and $425 \mu \mathrm{l}$ for 12- and 24well plates, respectively), cells were incubated for $60 \mathrm{~min}$ at $37^{\circ} \mathrm{C}$. An aliquot $(100 \mu \mathrm{l})$ of the extracellular solution was collected as a control sample for background ATP release. An OGD challenge was then applied by gently removing most of the remaining extracellular solution (875 and $300 \mu \mathrm{l}$ for 12 - and 24-well plates, respectively) and adding the OGD solution (1,000 and $400 \mu$ for 12- and 24-well 
plates, respectively), and then placing the plates in an airtight incubator where normal air was replaced with $100 \%$ argon. At the specified time points, the plate was carefully rocked again to ensure homogeneity of the extracellular solution, and samples (20 and $50 \mu \mathrm{l}$ for 12- and 24-well plates, respectively) were collected from each well for the luminometric ATP assay. The ATP concentration was measured by mixing 20 or $50 \mu \mathrm{l}$ of sample solution with 530 or $500 \mu \mathrm{l}$ normal Ringer solution and $50 \mu \mathrm{l}$ of luciferin-luciferase reagent. At this ratio, the ionic salt sensitivity of the luciferase reaction was negligible. When required, drugs were added to the OGD solution to give the final concentrations as indicated. Since $\mathrm{Gd}^{3+}$ is known to interfere with the luciferin-luciferase reaction [25], we supplemented the luciferin-luciferase assay mixture with $600 \mu \mathrm{M}$ EDTA when the samples contained $\mathrm{Gd}^{3+}$. Other drugs employed in the present study had no significant effect on the luciferin-luciferase reaction.

\section{Biosensor ATP measurements}

To measure the local concentration of ATP released from single astrocytes, the biosensor technique was employed, as described previously [23]. ATP-dependent changes in whole-cell $\mathrm{P} 2 \mathrm{X}_{2}$ receptor currents were recorded from a biosensor HEK-P2X $\mathrm{X}_{2}$ cell at a holding potential of $-50 \mathrm{mV}$. Before the actual measurements of ATP release, a calibration curve was constructed by recording the biosensor responses to known concentrations of ATP. The biosensor cell in the whole-cell configuration was lifted by means of a micromanipulator and positioned near a handmade local microperfusion device consisting of several inlet tubes. Each of the inlet tubes was filled with a different concentration of ATP solution ranging from 1 to $20 \mu \mathrm{M}$. To minimize the effect of desensitization, the sensor cell was exposed to ATP puffed every $3 \min$ for $1 \mathrm{~s}$ to a maximum of five applications. During the measurements of ATP from an individual astrocyte under OGD stress, the biosensor cell was gently touched to the surface of the target cell. From the recorded currents, the concentration of ATP was calculated according to the calibration curve.

\section{Patch-clamp experiments and data analysis}

Patch-clamp experiments were performed, as described previously [17, 19], using an EPC-9 patch-clamp system (HEKA Electronics, Lambrecht/Pfalz, Germany). The membrane potential was controlled by shifting the pipette potential $(V p)$. Currents were sampled at $3 \mathrm{kHz}$ and filtered at $1 \mathrm{kHz}$. Data acquisition and analysis were done using Pulse+PulseFit (HEKA Electronics, Lambrecht/Pfalz, Germany). Whenever the bath $\mathrm{Cl}^{-}$concentration was altered, a salt bridge containing $3 \mathrm{M} \mathrm{KCl}$ in $2 \%$ agarose was used to minimize variations of the bath electrode potential. Liquid junction potentials were corrected online. All experiments were performed at room temperature $\left(23-25^{\circ} \mathrm{C}\right)$.

Single-channel amplitudes were measured by manually placing a cursor at the open and closed channel levels. Background currents were subtracted and the mean patch currents were measured at the beginning (first $25-30 \mathrm{~ms}$ ) of current traces in order to minimize the contribution of voltage-dependent current inactivation. The reversal potentials were calculated by fitting $\mathrm{I}-\mathrm{V}$ curves to a second-order polynomial [18] or measured directly from ramp currents. Permeability ratios were calculated, as described previously $[19,21]$. Data were analyzed in Origin 6 or 7 (OriginLab Corporation, Northampton, MA, USA). Pooled data are given as means \pm SEM of $n$ observations.

Statistical differences of the data were evaluated by analysis of variance (ANOVA) and the paired or unpaired Student's $t$-test where appropriate and were considered significant at $P<0.05$.

\section{Results}

OGD induces massive release of ATP from astrocytes

Under control conditions, when astrocytes were incubated in standard Ringer solution, the basal release of ATP was very low and did not exceed $0.25 \mathrm{nM}$ over $40 \mathrm{~min}$ incubation time (Fig. 1a: open circles). In contrast, when cells were transferred to OGD conditions, the bulk ATP in the incubation medium rapidly increased from the basal level to a peak level of approximately $2 \mathrm{nM}$ within 15 $20 \mathrm{~min}$. After this period, the extracellular ATP concentration remained high up to $30 \mathrm{~min}$ of incubation and then slightly decreased at $40 \mathrm{~min}$ of incubation under OGD stress (Fig. 1a: filled circles).

In the following pharmacological experiments, we used an incubation time point of $20 \mathrm{~min}$, when the net ATP release induced by OGD reached a steady-state level. Application of extracellular $50 \mu \mathrm{M} \mathrm{Gd}^{3+}$ nearly completely inhibited OGD-induced ATP release from cultured mouse astrocytes. Arachidonic acid $(20 \mu \mathrm{M})$ also significantly inhibited OGD-induced ATP release. In contrast, OGDinduced ATP release was not significantly affected by blockers of the volume-sensitive outwardly rectifying (VSOR) $\mathrm{Cl}^{-}$channel, phloretin $(100 \mu \mathrm{M})$ and glibenclamide $(200 \mu \mathrm{M})$, of the CFTR $\mathrm{Cl}^{-}$channel, glibenclamide $(200 \mu \mathrm{M})$, and of the transporter MRP, probenecid $(1 \mathrm{mM})$. Also, the ATP release was not sensitive to inhibitors of connexin or pannexin hemichannels, 1-octanol $(2 \mathrm{mM})$ and carbenoxolone $(100 \mu \mathrm{M})$, and a blocker of the $\mathrm{P}_{2} \mathrm{X}_{7}$ receptor, brilliant blue $\mathrm{G}(1 \mu \mathrm{M})$. Preincubation of the cells with an inhibitor of vesicular transport, brefeldin A (BFA, 
Fig. 1 OGD-induced ATP release from astrocytes detected by the luciferin-luciferase assay. a Time course of ATP release during incubation with control standard Ringer solution (open circles) and with the OGD solution (filled circles). b Pharmacological profiles of ATP release measured 20 min after application of OGD solution. Each data point or column represents the mean \pm SEM (vertical bar).

* Significantly different from the control OGD value in the absence of drugs at $P<0.05$ a

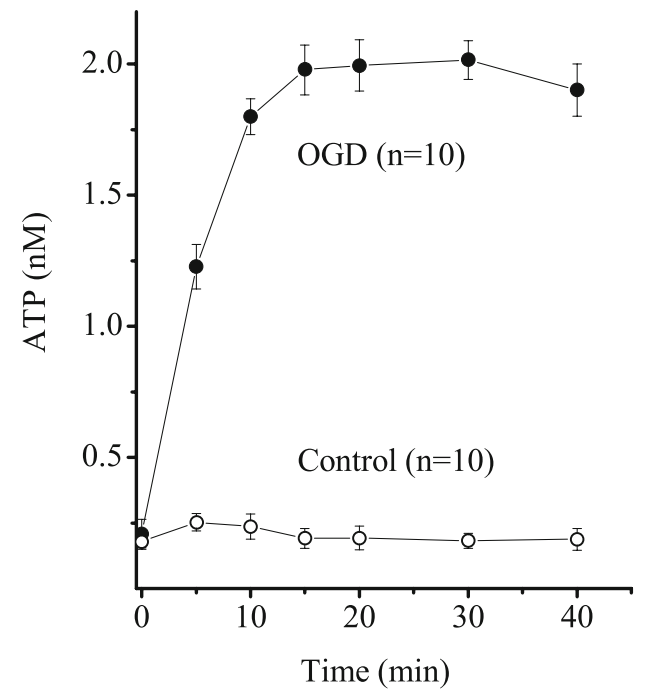

b

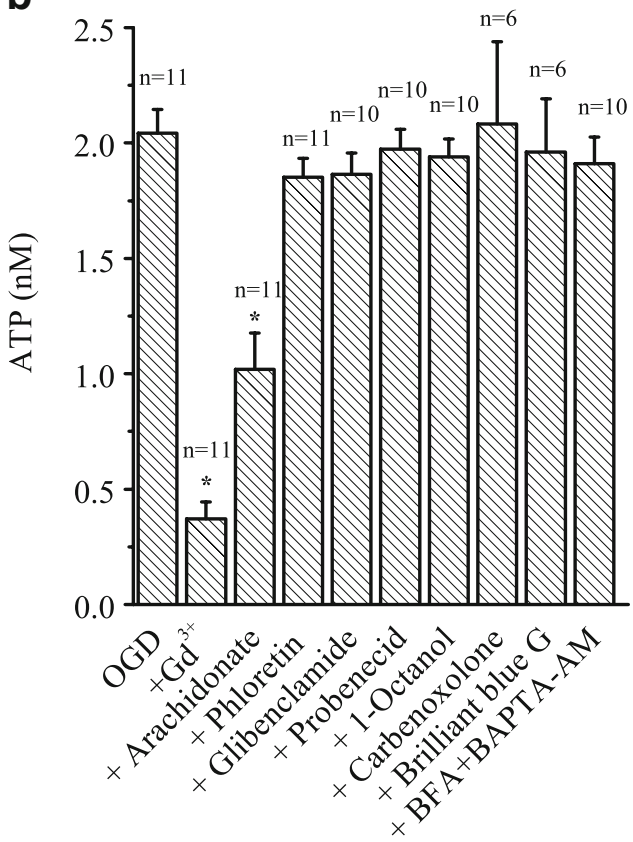

$5 \mu \mathrm{M}$ ), for 120 min and together with an intracellular $\mathrm{Ca}^{2+}$ chelator, BAPTA-AM $(5 \mu \mathrm{M})$, for $30 \mathrm{~min}$ had no significant effect on the OGD-induced release of ATP (Fig. 1b).

a
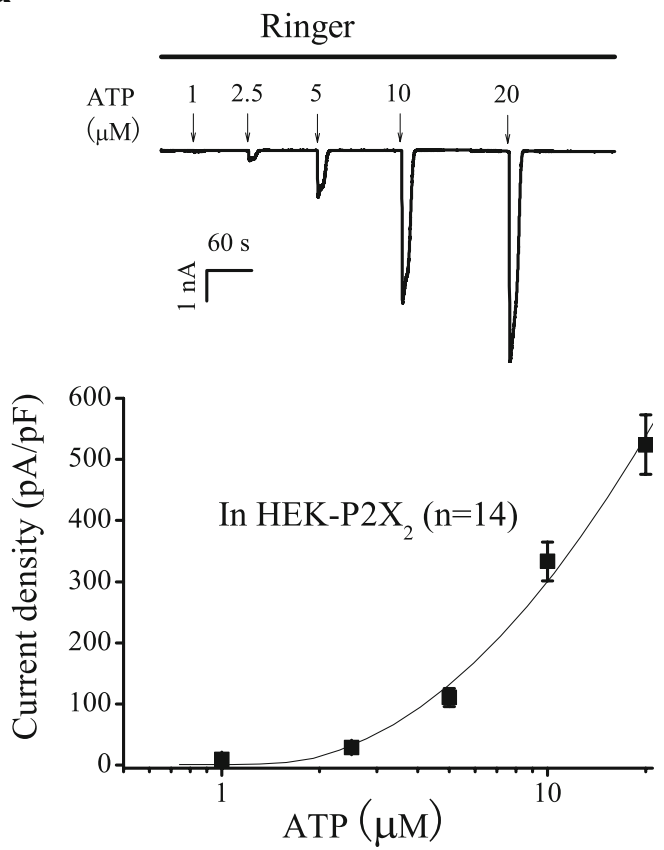

Fig. 2 Cell surface ATP release induced by OGD from single astrocytes. a Calibration of ATP measurements by the biosensor technique. Top panel: representative current responses evoked by puff applications of $1-20 \mu \mathrm{M}$ ATP in a biosensor HEK-P2X $\mathrm{X}_{2}$ cell under whole-cell clamp. Bottom panel: concentration-response curve of the ATP-induced currents recorded from biosensor cells. Each data point represents the mean \pm SEM (vertical bar). b Representative current
In order to detect ATP release at the surface of single astrocytes, we employed a biosensor ATP assay technique [23]. We first established the calibration curve by recording the responses of biosensor HEK-P2X $\mathrm{X}_{2}$ cells to different

b

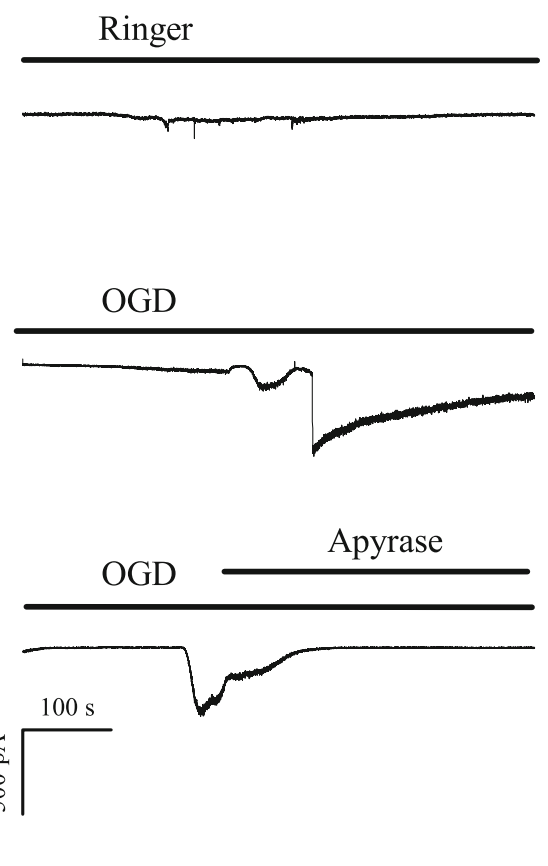

traces recorded from biosensor cells in close proximity to target astrocytes after perfusion with standard Ringer solution (top panel) or with the OGD solution in the absence (middle panel) or presence (bottom panel) of $0.1 \mathrm{mg} / \mathrm{ml}$ apyrase, which was applied after current responses appeared. When apyrase was applied from the beginning of OGD application, no current response was observed in biosensor cells positioned next to astrocytes (data not shown) 
a

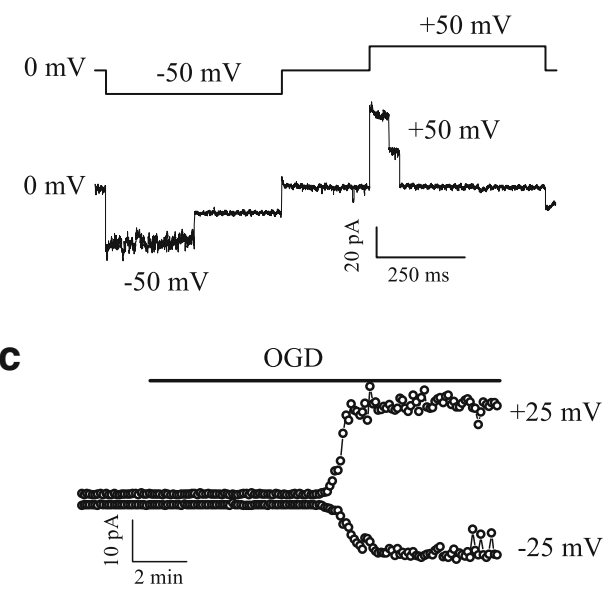

Fig. 3 OGD-induced single-channel activity of the maxi-anion channel in cell-attached patches on astrocytes. a Representative current trace recorded during application of alternating pulses (the protocol shown in inset above). Note that voltage-dependent inactivation of channel activity took place shortly after application of step pulses to $\pm 50 \mathrm{mV}$.

known concentrations of ATP (Fig. 2a). We then gently put the biosensor cell close to the surface of a target astrocyte and recorded the whole-cell current responses from the biosensor cell. As shown in Fig. 2b (top panel), virtually no ATP-evoked currents were observed during perfusion of standard Ringer solution. However, inward current spikes were consistently recorded upon perfusion with OGD solution after a lag period of $7.2 \pm 1.0 \mathrm{~min}(n=5)$ (Fig. 2b: middle panel). The OGD-induced inward current responses b

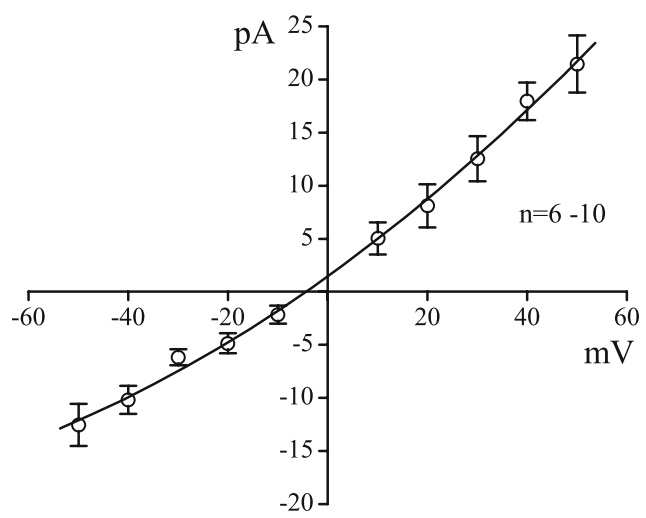

b Current-voltage (I-V) relationship for unitary events of the maxianion channel. The reversal potential was $-4.6 \pm 1.9 \mathrm{mV}$. Each data point represents the mean \pm SEM (vertical bar). $\mathbf{c}$ Time course of OGDinduced activation of the maxi-anion channel. The mean patch currents recorded at $\pm 50 \mathrm{mV}$ are plotted as a function of time

were eliminated by application of an ATP-hydrolyzing enzyme, apyrase (Fig. 2b: bottom panel). OGD-induced responses were never observed in biosensor cells alone which were positioned remote from target astrocytes. Using the calibration curve, the local ATP concentration was estimated to be $3.7 \pm 0.1 \mu \mathrm{M}$ at the surface of single astrocytes subjected to OGD stress.

From these data, it is concluded that in response to OGD stress, $\mathrm{Gd}^{3+}-$ and arachidonic acid-sensitive ATP release
Fig. 4 Pharmacological profile of OGD-activated maxi-anion channel events in inside-out patches excised from astrocytes. a Representative current traces recorded during application of alternating pulses (the protocol shown in inset above) in the absence (control) and presence of $\mathrm{Gd}^{3+}(50 \mu \mathrm{M}$ in the pipette), arachidonic acid $(20 \mu \mathrm{M}$ in the bath), and phloretin $(100 \mu \mathrm{M}$ in the bath). b Effects of $\mathrm{Gd}^{3+}$, arachidonic acid, and phloretin on the OGD-induced singlechannel activity recorded at \pm $25 \mathrm{mV}$. Data are normalized to the mean currents before application of drugs. Each column represents the mean \pm SEM (vertical bar). *Significantly different from the control value at $P<0.05$ a

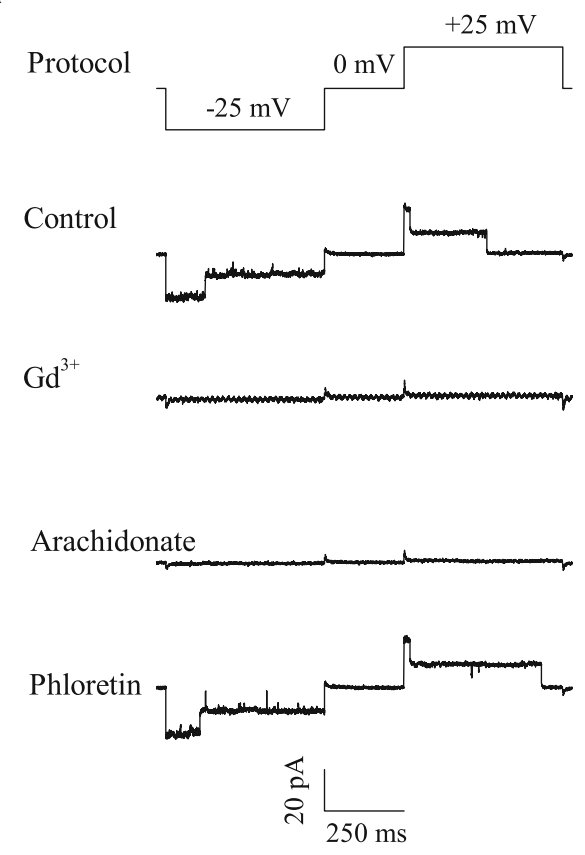

b

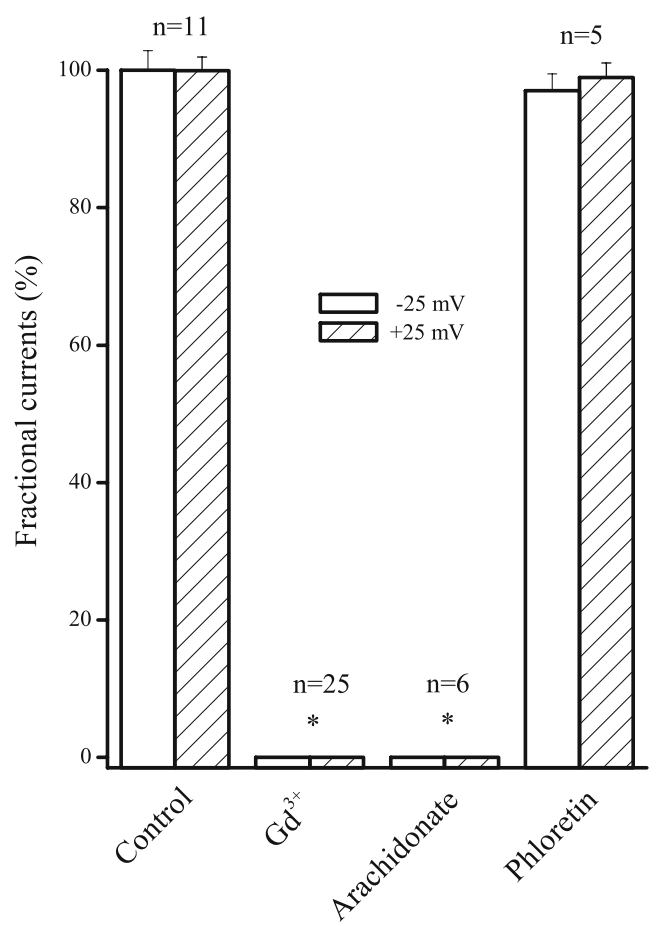


Fig. 5 Representative ramp I-V records of single-channel events of the maxi-anion channel preactivated by OGD in an insideout patch exposed to standard Ringer solution (chloride) and one exposed to $100 \mathrm{mM}$ $\mathrm{Na}_{4}$ ATP solution (ATP). The inward currents recorded in the ATP-exposed patch represent $\mathrm{ATP}^{4-}$ currents. The amplitude of outward currents became smaller when $\mathrm{ATP}^{4-}$ was present in the bath, suggesting a blocking of currents by $\mathrm{ATP}^{4-}$, as observed in mammary $\mathrm{C} 127$ cells [19]

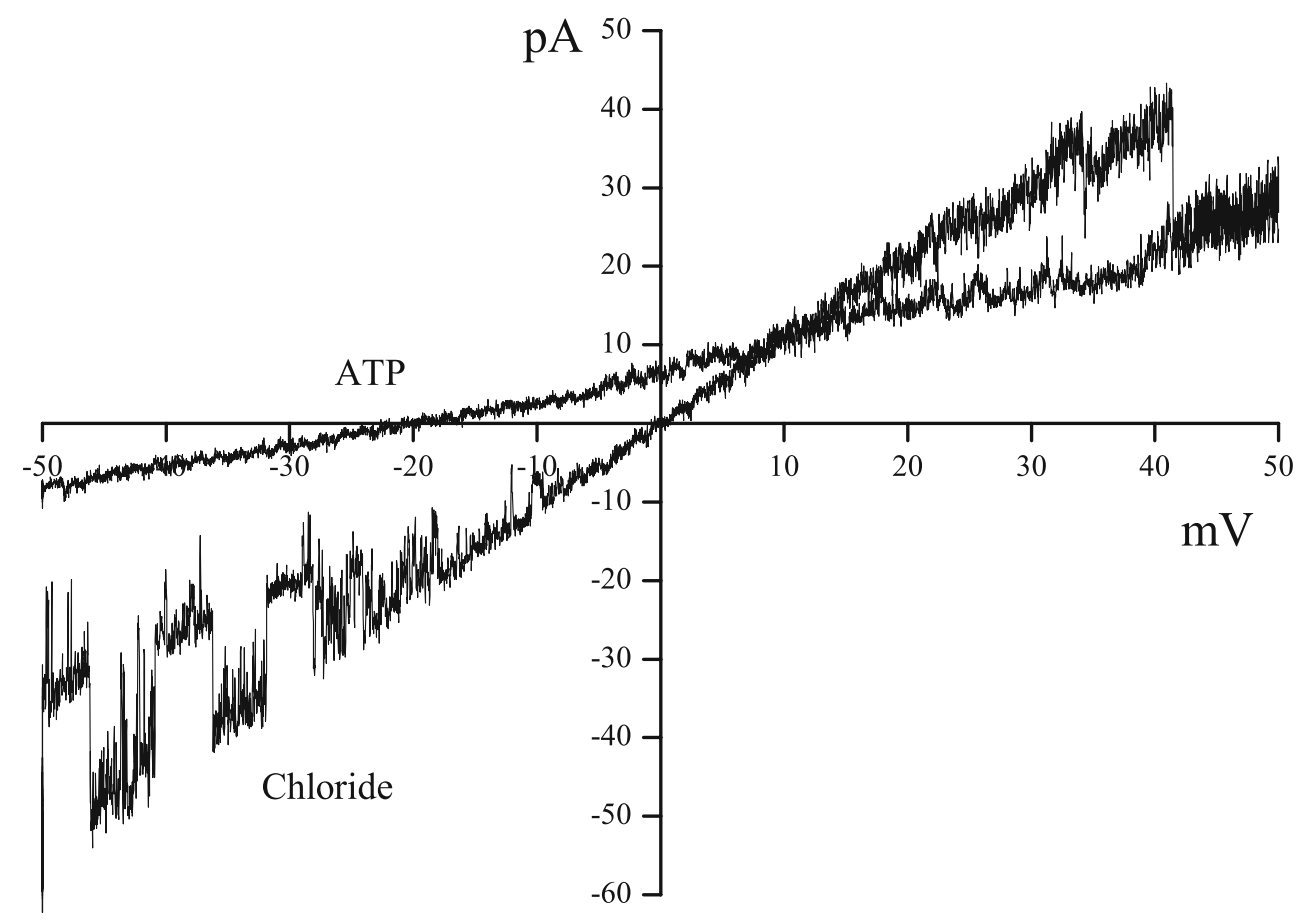

from astrocytes is induced, increasing the extracellular ATP concentration to a level high enough to stimulate most types of purinergic receptors.

OGD activates ATP-conductive maxi-anion channels in astrocytes

The fact that both $\mathrm{Gd}^{3+}$ and arachidonic acid are potent blockers of maxi-anion channels in mouse astrocytes [17] suggests that OGD-induced ATP release involves the activity of maxi-anion channels. In cell-attached experiments, OGD stress actually induced activation of anion channels with a large conductance (Fig. 3a), as seen to occur in a similar manner upon stimulation by hypotonicity or chemical ischemia in mouse astrocytes [17]. The unitary I-V relationship for these events exhibited slight outward rectification, and the mean slope conductance was $427 \pm$ $23 \mathrm{pS}$ at $+60 \mathrm{mV}$ and $262 \pm 21 \mathrm{pS}$ at $-50 \mathrm{mV}$ (Fig. 3b). In cell-attached patches, OGD-induced activation of the maxianion channel started with a lag time of several minutes and reached its peak within $10 \mathrm{~min}(8.8 \pm 1.2 \mathrm{~min}, n=6)$, as shown in Fig. 3c.

The single-channel activity induced by OGD persisted after excision of the patch (Fig. 4: control). In the inside-out mode, however, the channel activity was blocked by extracellular $\mathrm{Gd}^{3+}(50 \mu \mathrm{M})$ in backfilled pipettes and by intracellular (bath) application of $20 \mu \mathrm{M}$ arachidonic acid (Fig. 4: $\mathrm{Gd}^{3+}$ and arachidonate). In contrast, phloretin $(100 \mu \mathrm{M})$ failed to affect the maxi-anion channel activity (Fig. 4: phloretin).
In inside-out patches, when the bath solution was changed from standard Ringer solution to a $100 \mathrm{mM}$ $\mathrm{Na}_{4}$ ATP solution, the reversal potential shifted from $0 \mathrm{mV}$ to $-20.6 \pm 0.9 \mathrm{mV}(n=6)$; from this result, a $\mathrm{P}_{\mathrm{ATP}} / \mathrm{P}_{\mathrm{Cl}}$ value was estimated to be $0.11 \pm 0.01$ (Fig. 5).

These results indicate that in astrocytes OGD stress activates a maxi-anion channel which can conduct anionic forms of ATP and is sensitive to $\mathrm{Gd}^{3+}$ and arachidonic acid.

\section{Discussion}

In the brain, bidirectional communication takes place between glial cells and neurons. Astrocytes clear synaptically released glutamate from the synaptic cleft, receive signals from neurons at certain receptors, and release molecules, called gliotransmitters, that modulate synaptic transmission, protect neurons from impairment, or repair neuronal tissues after damage. ATP and glutamate represent major gliotransmitters. It has been reported that astrocytes release ATP in response to a number of stimuli, including receptor activation [5-7], mechanical or osmotic perturbation [8-11], and deprivation of extracellular $\mathrm{Ca}^{2+}[8,9,12]$. The present study demonstrated that astrocytes also respond to ischemic stress mimicked by OGD with ATP release (Figs. 1a and 2b). ATP released from astrocytes has been shown to regulate glutamatergic synaptic transmission $[6,7$, 10], inhibit excitability of retinal neurons [26], activate microglia [27, 28], modulate some functions of astrocytes [11], and protect astrocytes themselves from $\mathrm{H}_{2} \mathrm{O}_{2}$ - 
induced cell death [29]. Pathophysiological functions of ischemia-induced ATP release from astrocytes remain to be elucidated.

There has been much controversy about the pathway of nonlytic release of ATP from a variety of cell types [30, 31]. The candidate pathways proposed for astrocytic ATP release include connexin hemichannels [8], MRP [11], $\mathrm{P}^{2} \mathrm{X}_{7}$ receptors [12], and exocytotic vesicular transport [9]. In the present study, however, OGD-induced ATP release was shown to be insensitive to blocking agents for connexin hemichannels (1-octanol, carbenoxolone), MRP (probenecid), $\mathrm{P}_{2} \mathrm{X}_{7}$ receptors (brilliant blue $\mathrm{G}$ ), and exocytosis (BFA plus BAPTA-AM) (Fig. 1b). Recently, it was reported that pannexins form ATP-conductive channels when expressed in Xenopus oocytes [32]. However, a possible involvement of the pannexin hemichannel in OGD-induced ATP release from astrocytes can be ruled out by the present observation (Fig. 1b) of insensitivity to carbenoxolone, which is a potent blocker of not only connexin but also pannexin hemichannels as well [33]. Although VSOR anion channels were shown to be permeable to ATP at large positive potentials in endothelial cells [34], potent VSOR blockers (phloretin, glibenclamide) failed to affect OGD-induced ATP release from astrocytes in the present study (Fig. 1b). In contrast, $\mathrm{Gd}^{3+}$ and arachidonic acid were found to prominently suppress ATP release from mouse astrocytes subjected to OGD (Fig. 1b). Our previous study [17] showed that in mouse astrocytes, maxi-anion channels are activated by chemical ischemia and are sensitive to both $\mathrm{Gd}^{3+}$ and arachidonic acid. The present study demonstrated that maxi-anion channels are activated by OGD (Fig. 3) and that OGD-activated maxianion channels are sensitive to $\mathrm{Gd}^{3+}$ and arachidonic acid (Fig. 4) and can conduct anionic forms of ATP (Fig. 5). On balance, it appears that the maxi-anion channel serves as a major pathway for OGD-induced ATP release from mouse astrocytes in primary culture. Our preliminary study has shown that in mouse hippocampal slices, astrocytes also respond to OGD with the activation of maxi-anion channels (H.-T. Liu, R.Z. Sabirov, Y. Okada, unpublished observations). Since ischemia-like stress was reported to induce ATP release from hippocampal slices [13], it is highly possible that the maxi-anion channel also provides a pathway for ischemia-induced ATP release from astrocytes in slice preparations.

Acknowledgements This work was supported by Grants-in-Aid for Scientific Research from JSPS and for Scientific Research on Priority Areas from MEXT. The authors thank to E.L. Lee for reading the manuscript, K. Shigemoto and M. Ohara for technical assistance, and T. Okayasu for secretarial assistance.

\section{References}

1. Fields RD, Stevens-Graham B (2002) New insights into neuron-glia communication. Science 298:556-562

2. Hatton GI (2002) Glial-neuronal interactions in the mammalian brain. Adv Physiol Educ 26:225-237

3. Hansson E, Ronnback L (2003) Glial neuronal signaling in the central nervous system. FASEB J 17:341-348

4. Araque A, Perea G (2004) Glial modulation of synaptic transmission in culture. Glia 47:241-248

5. Cotrina ML, Lin HJ, Alves-Rodrigues A et al (1998) Connexins regulate calcium signaling by controlling ATP release. Proc Natl Acad Sci USA 95:15735-15740

6. Zhang JM, Wang HK, Ye CQ et al (2003) ATP released by astrocytes mediates glutamatergic activity-dependent heterosynaptic suppression. Neuron 40:971-982

7. Gordon GR, Baimoukhametova DV, Hewitt SA et al (2005) Norepinephrine triggers release of glial ATP to increase postsynaptic efficacy. Nat Neurosci 8:1078-1086

8. Stout CE, Costantin JL, Naus CC, Charles AC (2002) Intercellular calcium signaling in astrocytes via ATP release through connexin hemichannels. J Biol Chem 277:10482-10488

9. Coco S, Calegari F, Pravettoni E et al (2003) Storage and release of ATP from astrocytes in culture. J Biol Chem 278:1354-1362

10. Koizumi S, Fujishita K, Tsuda M et al (2003) Dynamic inhibition of excitatory synaptic transmission by astrocyte-derived ATP in hippocampal cultures. Proc Natl Acad Sci USA 100:11023-11028

11. Darby M, Kuzmiski JB, Panenka W et al (2003) ATP released from astrocytes during swelling activates chloride channels. J Neurophysiol 89:1870-1877

12. Suadicani SO, Brosnan CF, Scemes E (2006) P2X7 receptors mediate ATP release and amplification of astrocytic intercellular $\mathrm{Ca}^{2+}$ signaling. J Neurosci 26:1378-1385

13. Jurányi Z, Sperlágh B, Vizi ES (1999) Involvement of $P_{2}$ purinoceptors and the nitric oxide pathway in $\left[{ }^{3} \mathrm{H}\right]$ purine outflow evoked by short-term hypoxia and hypoglycemia in rat hippocampal slices. Brain Res 823:183-190

14. Nowak L, Ascher P, Berwald-Netter Y (1987) Ionic channels in mouse astrocytes in culture. J Neurosci 7:101-109

15. Sonnhof U (1987) Single voltage-dependent $\mathrm{K}^{+}$and $\mathrm{Cl}^{-}$channels in cultured rat astrocytes. Can J Physiol Pharmacol 65:1043-1050

16. Jalonen T (1993) Single-channel characteristics of the largeconductance anion channel in rat cortical astrocytes in primary culture. Glia 9:227-237

17. Liu H, Tashmukhamedov BA, Inoue H et al (2006) Roles of two types of anion channels in glutamate release from mouse astrocytes under ischemic or osmotic stress. Glia 54:343-357

18. Sabirov RZ, Okada Y (2004) Wide nanoscopic pore of maxianion channel suits its function as an ATP-conductive pathway. Biophys J 87:1672-1685

19. Sabirov RZ, Dutta AK, Okada Y (2001) Volume-dependent ATPconductive large-conductance anion channel as a pathway for swelling-induced ATP release. J Gen Physiol 118:251-266

20. Bell PD, Lapointe JY, Sabirov R et al (2003) Macula densa cell signaling involves ATP release through a maxi anion channel. Proc Natl Acad Sci USA 100:4322-4327

21. Dutta AK, Sabirov RZ, Uramoto H, Okada Y (2004) Role of ATP-conductive anion channel in ATP release from neonatal rat cardiomyocytes in ischaemic or hypoxic conditions. J Physiol 559 (Pt 3):799-812

22. Zhang XD, Morishima S, Ando-Akatsuka Y et al (2004) Expression of novel isoforms of the $\mathrm{ClC}-1$ chloride channel in astrocytic glial cells in vitro. Glia 47:46-57 
23. Hayashi S, Hazama A, Dutta AK et al (2004) Detecting ATP release by a biosensor method. Sci STKE 258:1-14

24. Hazama A, Shimizu T, Ando-Akatsuka Y et al (1999) Swellinginduced, CFTR-independent ATP release from a human epithelial cell line. Lack of correlation with volume-sensitive $\mathrm{Cl}^{-}$channels. J Gen Physiol 114:525-533

25. Boudreault F, Grygorczyk R (2002) Cell swelling-induced ATP release and gadolinium-sensitive channels. Am J Physiol Cell Physiol 282:C219-C226

26. Newman EA (2003) Glial cell inhibition of neurons by release of ATP. J Neurosci 23:1659-1666

27. Inoue K (2002) Microglial activation by purines and pyrimidines. Glia 40:156-163

28. Xiang Z, Chen M, Ping J et al (2006) Microglial morphology and its transformation after challenge by extracellular ATP in vitro. $\mathrm{J}$ Neurosci Res 83:91-101
29. Shinozaki Y, Koizumi S, Ishida S, Sawada J, Ohno Y, Inoue K (2005) Cytoprotection against oxidative stress-induced damage of astrocytes by extracellular ATP via P2Y $\mathrm{Y}_{1}$ receptors. Glia 49:288-300

30. Schwiebert EM, Zsembery A (2003) Extracellular ATP as a signaling molecule for epithelial cells. Biochim Biophys Acta 1615:7-32

31. Sabirov RZ, Okada Y (2005) ATP release via anion channels. Purinergic Signalling 1:311-328

32. Bao L, Locovei S, Dahl G (2004) Pannexin membrane channels are mechanosensitive conduits for ATP. FEBS Lett 572:65-68

33. Bruzzone R, Barbe MT, Jakob NJ, Monyer H (2005) Pharmacological properties of homomeric and heteromeric pannexin hemichannels expressed in Xenopus oocytes. J Neurochem 92:1033-1043

34. Hisadome K, Koyama T, Kimura C et al (2002) Volume-regulated anion channels serve as an auto/paracrine nucleotide release pathway in aortic endothelial cells. J Gen Physiol 119:511-520 